ORIGINAL ARTICLE

\title{
Factors predictive of intravenous fluid administration errors in Australian surgical care wards
}

\author{
P Y Han, I D Coombes, B Green
}

Qual Saf Health Care 2005;14:179-184. doi: 10.1136/qshc.2004.010728

See end of article for authors' affiliations

.....................

Correspondence to: Dr B Green, Center for Drug Development Science, University of California San Francisco, UCDC Center, 1608 Rhode Island Ave, Washington, DC 20036, USA; greenb@pharmacy. uq.edu.au

Accepted for publication 4 October 2004

\begin{abstract}
Background: Intravenous (IV) fluid administration is an integral component of clinical care. Errors in administration can cause detrimental patient outcomes and increase healthcare costs, although little is known about medication administration errors associated with continuous IV infusions.

Objectives: (1) To ascertain the prevalence of medication administration errors for continuous IV infusions and identify the variables that caused them. (2) To quantify the probability of errors by fitting a logistic regression model to the data.

Methods: A prospective study was conducted on three surgical wards at a teaching hospital in Australia. All study participants received continuous infusions of IV fluids. Parenteral nutrition and non-electrolyte containing intermittent drug infusions (such as antibiotics) were excluded. Medication administration errors and contributing variables were documented using a direct observational approach.

Results: Six hundred and eighty seven observations were made, with 124 (18.0\%) having at least one medication administration error. The most common error observed was wrong administration rate. The median deviation from the prescribed rate was $-47 \mathrm{ml} / \mathrm{h}$ (interquartile range -75 to $+33.8 \mathrm{ml} / \mathrm{h}$ ). Errors were more likely to occur if an IV infusion control device was not used and as the duration of the infusion increased.

Conclusions: Administration errors involving continuous IV infusions occur frequently. They could be reduced by more common use of IV infusion control devices and regular checking of administration rates.
\end{abstract}

n ntravenous (IV) fluid replacement is a routine pharmacological intervention for patients who are vomiting, have diarrhoea, draining tubes in situ, wounds with excessive fluid loss, or inadequate oral fluid intake. Administration of wrong concentrations or types of IV fluid can be fatal, ${ }^{1}$ and errors in rate of administration can cause clinical complications such as heart failure or volume depletion. Medication administration errors (MAEs) therefore cause direct patient harm, ${ }^{2-5}$ but are also known to increase health care costs. ${ }^{5-8}$ The prevalence of MAEs arising from oral medications given during regular drug rounds has been reported at between $3.5 \%{ }^{9}$ and $19 \%,{ }^{10}$ which has provoked public interest as many are considered preventable. ${ }^{11}$

Errors in the workplace are not only confined to health care, with the engineering and aviation industry also recognising their inevitability. Research from these disciplines has attributed error occurrence to working environments, ${ }^{12}$ a philosophy that has now been adopted by healthcare institutions. Within the healthcare environment, institutions must seek to acquire knowledge about error prone situations and identify variables associated with them in an attempt to change systems and reduce future events. ${ }^{13}{ }^{14}$ This requires some commitment to specific research activities, but should be complemented by a non-punitive reporting system to facilitate knowledge acquisition from errors arising in normal daily practice. Previous data have indicated that the variables primarily responsible for MAEs are nurses' knowledge of the medications, their length of experience, their failure to follow guidelines, the time of day, the day of the week, workload and staffing levels. ${ }^{15-17}$

The Princess Alexandra Hospital in Brisbane, Australia has accepted that environmental issues will contribute towards medication errors and has created a multidisciplinary team dedicated to reducing medication administration risk. It has undergone a process of medication system redesign in response to local incidents and has introduced system changes that may have been partly successful in reducing errors (not currently quantified). These changes include standardisation of medication charts and infusion control devices across all wards as well as replacement of undiluted potassium chloride with premixed IV fluids.

Most of the literature on MAEs to date has focused on oral medications or medications administered during regular drug rounds. A few examples of MAEs arising from IV bolus doses or intermittent infusions have been reported, ${ }^{18-21}$ but we have not been able to find any information describing the prevalence of MAEs associated with continuous IV infusions. This could be due to the complexity of identifying them in a research environment as continuous IV infusions are usually replaced by nursing staff once the contents of the previous bag have been infused. This is dissimilar to oral or IV bolus drugs (which are usually administered at set times) and requires an observer to be present at the point of preparation and/or administration. Due to the lack of information on MAEs from continuous IV infusions, we aimed to determine their prevalence and identify the variables that caused them. We also aimed to quantify the probability of an error by fitting a logistic regression model to the data.

\section{METHODS}

Identification of medication administration errors

Data were collected by an observer (PYH) from three surgical wards at a teaching hospital in Brisbane, Australia. The observer was trained by a member of the hospital's medication safety team (an experienced intensive care nurse) and spent a day on each study ward to familiarise herself with standard processes for IV infusion preparation and administration. The wards comprised approximately 80 beds and 50 nurses with errors identified using a direct observational technique. ${ }^{22}$ The three wards chosen for the study were located in close proximity to each other, allowing the observer to move freely between them. Infusions currently running were directly identifiable by the observer. As it was not possible for the observer to be physically located on all 
three wards concurrently, nurses were asked to call the observer when they were preparing and setting up IV infusions. Also, in order to maximise data retrieval, the observer screened medication charts for each patient on each ward twice daily, immediately following the morning and afternoon medical rounds. This allowed the observer to check for doses that had been prescribed immediately on the rounds and also to identify the time of the next expected dose.

A 1 week run-in period was conducted to allow nurses to become familiar with the observer's presence and also to encourage nurses to call the observer during dose preparation. Both the preparation and administration of IV fluids were observed where possible. All clinical staff practising on the study wards were made aware that the study aimed to identify underlying system risks which would be used to implement system changes in the prescribing or administration of IV fluids. Nurses were also made aware that the study did not intend to assess individual clinical practices or standards of care.

\section{Subjects and data collection}

All patients admitted to the study wards were eligible for inclusion in the trial, provided they were prescribed continuous infusions of IV fluids. Patients administered only parenteral nutrition (TPN) were excluded as they were reviewed and monitored daily by the TPN team (which includes a specialist nurse), and all TPN is run via an IV

Table 1 Definitions of medical administration errors (MAEs) used in the study

\begin{tabular}{ll}
\hline Type of MAE & Definition \\
\hline Wrong administration rate & $\begin{array}{l}\text { Patient receives IV fluid at a rate that is } \\
\text { faster or slower than the rate prescribed. } \\
\text { Dose omission }\end{array}$ \\
Patient does not receive his/her IV fluid \\
due to failure to replace the empty IV \\
fluid bag or failure to refill the burette. \\
Patient receives IV fluid after the order \\
was cancelled, put on hold, or for which \\
the physician did not write a \\
prescription.
\end{tabular}

infusion control device. Exclusion seemed prudent to prevent bias due to differing standards of care. Also, as the primary focus of this study was to evaluate MAEs from continuous infusions, non-electrolyte containing intermittent drug infusions (such as antibiotic infusions administered in a small bag of IV fluid) were also excluded. Data collection took place from Monday to Friday between 09.00 and 16.00 hours (day shift) and between 20.00 and 03.00 hours (night shift) over a 4 week period in March 2003. Observations were permitted without the nurse being present.

The following data were recorded at each observation: type and amount of IV fluid selected and electrolyte added, type of infusion device used, rate of infusion, and type of IV line. These data were then compared retrospectively with the legal prescription on the medication chart to detect if any errors had occurred during the preparation or administration of the IV fluid. For this study, an MAE was defined as a deviation from the prescriber's legal prescription. It should be noted that, in the study institution, the legal prescription is written on the medication chart which can be used to administer multiple bags of IV fluids. The medication chart is signed by the nurse each time the IV fluid is administered. The definitions for each type of error are shown in table 1 and mimic that presented in the literature by Taxis and Barber. ${ }^{19}$ Additional data such as demographics and biochemical test results were

Table 2 Variables collected that describe the patients' health status, treatment, and environment

\begin{tabular}{|c|c|}
\hline Variable & Definition \\
\hline $\begin{array}{l}\text { IV infusion control } \\
\text { device }\end{array}$ & $\begin{array}{l}\text { An automated volumetric infusion device that } \\
\text { provides an accurate infusion of IV fluids at a rate } \\
\text { and volume determined by the clinician. The } \\
\text { converse would be a controlled regulator giving } \\
\text { set which is non-automated and requires manual } \\
\text { adjustment of a regulator clamp to ensure correct } \\
\text { flow rate. }\end{array}$ \\
\hline IV lines & $\begin{array}{l}\text { Peripheral, peripherally inserted central catheter } \\
\text { (PICC), or central lines. }\end{array}$ \\
\hline Non-IV lines & $\begin{array}{l}\text { Nasogastric tubes and drainage tubes such as } \\
\text { urinary catheters and wound drainage tubes. }\end{array}$ \\
\hline Additive & Any electrolyte added to the bag of IV fluid. \\
\hline $\begin{array}{l}\text { Alternating bags of } \\
\text { fluid }\end{array}$ & $\begin{array}{l}\text { Refers to two different types of prescribed IV fluids } \\
\text { to be administered in an alternating sequence. }\end{array}$ \\
\hline Burette & $\begin{array}{l}\text { An optional piece of IV equipment that is placed } \\
\text { between the IV bag and IV administration set, } \\
\text { which is used to control the amount of fluid } \\
\text { available to be infused. }\end{array}$ \\
\hline Invasive procedures & $\begin{array}{l}\text { Includes surgery or endoscopy, whereas non- } \\
\text { invasive procedures would include admission for } \\
\text { observation or IV antibiotics. }\end{array}$ \\
\hline All permanent staff & $\begin{array}{l}\text { Indicates that all nurses working at the time of the } \\
\text { observation were permanently allocated to a } \\
\text { specific ward. The converse would be a mixture of } \\
\text { permanent and pooled staff where pooled nurses } \\
\text { work on different wards on different days }\end{array}$ \\
\hline Creatinine clearance & $\begin{array}{l}\text { Estimated glomerular filtration rate using the } \\
\text { Cockcroft-Gault equation, where total body } \\
\text { weight was used as the weight descriptor. }\end{array}$ \\
\hline Duration of infusion & $\begin{array}{l}\text { Length of time from initiation of administration to } \\
\text { the time the observation was made. }\end{array}$ \\
\hline Time of day & $\begin{array}{l}\text { Time that the observation was made. This was } \\
\text { treated as a binomial variable consisting of either } \\
\text { the day shift }(09.00 \text { to } 16.00 \text { hours) or the night } \\
\text { shift ( } 20.00 \text { to } 03.00 \text { hours). }\end{array}$ \\
\hline IV pain relief & IV infusions of opiates. \\
\hline $\begin{array}{l}\text { Level of nursing } \\
\text { experience }\end{array}$ & $\begin{array}{l}\text { Average score of all nurses working at the time } \\
\text { the observation was made based on their grade. } \\
\text { Graduate nurses, enrolled nurses, and re-entry } \\
\text { nurses were given a score of } 10 \text {, level } 1 \text { nurses } \\
\text { were given a score of } 20 \text {, and level } 2 \text { nurses were } \\
\text { given a score of } 30 \text {. }\end{array}$ \\
\hline $\begin{array}{l}\text { Occupancy of } \\
\text { bed bay }\end{array}$ & $\begin{array}{l}\text { Number of occupied beds within the bed bay } \\
\text { divided by the maximum number of beds within } \\
\text { the bed bay. }\end{array}$ \\
\hline
\end{tabular}


collected from the patients' medical, medication and fluid order charts, pathology results, the ward nursing rosters, and through direct observations at the bedside. Data describing the patients' health status, treatment, and their environment were also collected (table 2). Errors in appropriateness of prescribing ${ }^{14}$ were beyond the scope of this study.

\section{Ethical considerations}

The nurse preparing the IV fluid was required to provide verbal consent to be observed during the preparation and administration of an IV fluid. The nurse was also given the opportunity to correct any error before administration of the fluid to the patient. If it was evident that an administration error was about to occur that, in the observer's opinion, would have been clinically significant and potentially detrimental to the patient, the observer intervened to avert the error. In such cases the error was deemed to have occurred and included in the analysis within the error category. The observer also intervened if an actual error thought to be detrimental to the patient was already present-for example, a wrong administration rate. Any intervention was performed in a tactful and professional manner to avoid patient distress. As the observer was able to intervene to prevent significant medication errors, it was not possible to assess actual patient outcomes during this study. In order to ensure patient confidentiality, all identification labels were excluded from the data before analysis.

The study was approved by the research ethics committee of the Princess Alexandra Hospital, the human ethics subcommittee of the School of Pharmacy, University of Queensland, and the Assistant Director of Nursing for the Division of Surgery at the Princess Alexandra Hospital.

\section{Data analysis}

Descriptive statistical tests were performed using the statistical package NCSS. ${ }^{23}$ Observations were divided into those where an error occurred and those where an error did not occur. Data were compared using either a $\chi^{2}$ test, Fisher's exact test, two sample $t$ test (unequal variances), or MannWhitney $U$ test depending on the distribution and nature of the data. Odds ratios and 95\% confidence intervals (CI) were used to identify which variables to consider in a multivariable logistic regression model. The logistic regression analysis was chosen to describe the relationship between the outcome (error or no error) and the independent variables collected during the study. The probability of the response was calculated using the following logistic equation:

$$
\mathrm{p}=\frac{\exp (a+b x \ldots n y)}{(1+\exp [a+b x \ldots n y])}
$$

where $a+b x$ is termed the logit and $a, b \ldots n$ are parameters estimated from the fit of the logistic regression to the data. The model was built using NONMEM version $5^{24}$ and the G77 Fortran compiler. Variables were added manually to the

Table 3 Types of medication administration errors (MAEs)

\begin{tabular}{lll}
\hline & $\begin{array}{l}\text { No of errors } \\
(\mathbf{n = 1 2 6 )}\end{array}$ & $\%$ of total errors \\
\hline Wrong administration rate & 100 & 79.3 \\
Dose omission & 15 & 11.9 \\
Extra/unordered fluid & 5 & 4.0 \\
Wrong fluid & 4 & 3.2 \\
Wrong patient & 2 & 1.6 \\
${ }^{*}$ 126 errors were obtained from & \multirow{2}{*}{ 124 observations made. }
\end{tabular}

model in a forward sequential manner. Parameters that allowed for interaction between the variables were also added until the full model was obtained. A stepwise backward elimination was then conducted using the principle of parsimony to identify the final model. The likelihood ratio test statistic was used to discriminate between competing models with a change of 3.84 units or more (corresponding to $\mathrm{p}<0.05$ according to a $\chi^{2}$ distribution) considered statistically significant.

\section{RESULTS}

All nurses gave permission to be observed during the data collection period. Six hundred and eighty seven observations were made on 639 separate bags of IV fluid administered to 236 separate patients. Observation of fluid selection and addition of electrolytes (when required) were made on 90 occasions $(13.1 \%)$. One hundred and twenty four observations $(18.0 \%)$ contained at least one MAE and two observations contained two MAEs, producing a total of 126 MAEs. The most common MAE was wrong administration rate, accounting for $79.3 \%$ of the errors made (table 3 ). No MAEs were noted in the following error categories: wrong electrolyte, electrolyte omission, extra/unordered electrolyte, wrong dose, and wrong concentration.

The observer intervened on 52 occasions to either prevent an MAE occurring or to correct a current error. Examples of MAEs prevented include the following:

- A 1 litre bag of normal saline (0.9\% sodium chloride) with $40 \mathrm{mmol} / \mathrm{l}$ potassium chloride was about to be administered to a 55 year old patient who had nausea and vomiting, chronic pancreatitis, and hypokalaemia. The prescription had been changed to $4 \%$ dextrose in $0.18 \%$ sodium chloride with $40 \mathrm{mmol} / \mathrm{l}$ potassium chloride. The nurse administering the fluid had not noticed the prescription change.

- Two patients' medication charts had been switched at the bedside and the nurse was about to give an infusion of compound sodium lactate to the wrong patient.

Examples of MAEs that were identified and corrected include the following:

- An IV fluid was prescribed at a rate of $12 \mathrm{ml} / \mathrm{h}$ but observed to be running at $400 \mathrm{ml} / \mathrm{h}$.

- An IV infusion control device had been turned off for approximately 4 hours for a patient that was nil by mouth following a laparoscopic cholecystectomy for acute cholecystitis.

- An IV infusion control device had been turned off for an unknown duration in a 73 year old patient who was hypertensive and renally impaired. The patient should have been receiving a continuous infusion of compound sodium lactate following a resection of his colon.

\section{Impact of infusion control devices and duration of infusion on errors}

Many variables were identified that appeared to contribute towards MAEs, such as the presence of peripheral lines (odds ratio (OR) 3.48 (95\% CI 1.87 to 6.50)) and the duration of the infusion (OR 0.90 (95\% CI 0.86 to 0.93 )). Additional variables appeared to prevent MAEs such as use of an IV infusion control device (OR 0.12 (95\% CI 0.06 to 0.25 ) table 4 ). A number of factors that were thought to be important a priori (discussed in the introduction) were not found to contribute towards MAEs in this study (table 5). These included the number of co-morbidities (OR 1.01 (95\% CI 0.92 to 1.11 )), the number of doses given per day (OR 1.02 (95\% CI 0.99 to 
Table 4 Variables found to contribute towards or prevent medication administration errors (MAEs)

\begin{tabular}{|c|c|c|c|c|}
\hline Variable & $\begin{array}{l}\text { Error* } \\
(n=124)\end{array}$ & $\begin{array}{l}\text { No error* } \\
(n=563)\end{array}$ & $\begin{array}{l}\text { Odds ratio } \\
(95 \% \mathrm{Cl})\end{array}$ & $\mathrm{p}$ value \\
\hline $\begin{array}{l}\text { IV infusion control devices } \\
\text { Peripheral lines } \\
\text { Nasogastric feeds } \\
\text { All permanent staff } \\
\text { Invasive procedure } \\
\text { Duration of infusion (hour:minute) } \\
\text { No of days on IV fluids } \\
\text { Creatinine clearance }(\mathrm{ml} / \mathrm{min}) \\
\text { No of IV fluid orders } \\
\text { No of beds per bay } \\
\text { Age (years) } \\
\text { No of non-IV lines } \\
\text { No of IV and non-IV lines }\end{array}$ & $\begin{array}{l}9(7.26) \\
112(90.32) \\
1(0.81) \\
90(72.58) \\
67(54.03) \\
6: 49(3: 59-10: 20) \\
2(2-4) \\
97.5(65.4-124.0) \\
3(1-5) \\
4(4-4) \\
60(51-73) \\
0(0-1) \\
2(1-2)\end{array}$ & $\begin{array}{l}219(38.90) \\
410(72.82) \\
48(8.53) \\
476(84.55) \\
365(64.83) \\
4: 05(1: 30-6: 45) \\
3(2-6) \\
101.7(74.7-137.4) \\
3(2-7) \\
4(2-4) \\
56(46-71) \\
0(0-1) \\
2(1-3)\end{array}$ & $\begin{array}{l}0.12(0.06 \text { to } 0.25) \\
3.48(1.87 \text { to } 6.50) \\
0.09(0.01 \text { to } 0.64) \\
0.48(0.31 \text { to } 0.76) \\
0.64(0.43 \text { to } 0.94) \\
0.90(0.86 \text { to } 0.93) \\
1.09 \text { (1.03 to } 1.16) \\
1.01(1.00 \text { to } 1.01) \\
1.15(0.99 \text { to } 1.35) \\
0.79(0.65 \text { to } 0.96) \\
0.99(0.97 \text { to } 1.00) \\
1.30(1.05 \text { to } 1.62) \\
1.23(1.05 \text { to } 1.44)\end{array}$ & $\begin{array}{l}<0.001 \dagger \\
<0.001 \dagger \\
0.001 \ddagger \\
0.002 \dagger \\
0.024 \dagger \\
<0.001 \S \\
0.007 \S \\
0.014 \S \\
0.017 \S \\
0.018 \S \\
0.022 \S \\
0.024 \S \\
0.031 \S\end{array}$ \\
\hline
\end{tabular}

$1.05)$ ), and the level of nurse experience (OR 1.05 (95\% CI 0.95 to 1.17$)$ ).

The best multivariable logistic regression model that could be supported by the data using those factors shown in table 4 featured the presence of an IV infusion control device and the duration of infusion. The final logit (which is converted to probability using equation 1) was described by $-2.81-0.08$ $\times$ (duration of infusion) when an IV infusion control device is present and $-2.21+0.19 \times$ (duration of infusion) when an IV infusion control device is not present.

Figure 1 shows the simulated probability of error occurrence dependent upon use of an IV infusion control device and the duration of the infusion. This suggests that, in the presence of an IV infusion control device, error probability decreases as the duration of infusion increases, although the magnitude of this change is actually small. Of more significance is the increasing error probability with increasing infusion duration when an IV infusion control device is not present, rising from $10 \%$ at baseline to $91 \%$ if an infusion is given over 24 hours.

\section{DISCUSSION}

This study found that an error occurred in almost one fifth of continuous IV infusions administered to patients. This is comparable to studies of IV bolus doses and intermittent infusions where error prevalence has been reported to range from $10.3 \%$ to $49 \% .{ }^{19-21}$ We found that wrong administration rate was the most common type of error, and its occurrence could be significantly reduced by use of an IV infusion control device. When an infusion control device was not used we found that error probability increased as the duration of infusion lengthened.

Table 5 Variables not found to contribute towards or prevent medication administration errors (MAEs)

\begin{tabular}{|c|c|c|c|c|}
\hline Variable & $\begin{array}{l}\text { Error } \\
(n=124)^{*}\end{array}$ & $\begin{array}{l}\text { No error } \\
(n=563)^{*}\end{array}$ & $\begin{array}{l}\text { Odds ratio } \\
(95 \% \mathrm{Cl})\end{array}$ & $\mathrm{p}$ value \\
\hline Male & $58(46.78)$ & $294(52.22)$ & $0.80(0.54$ to 1.19$)$ & $0.272 \dagger$ \\
\hline Diabetes & $22(17.74)$ & $67(11.90)$ & $1.60(0.94$ to 2.70$)$ & $0.080 \dagger$ \\
\hline Hypertension & $30(24.19)$ & 131 (23.27) & $1.05(0.67$ to 1.66$)$ & $0.826+$ \\
\hline Congestive heart failure & $4(3.23)$ & $11(1.95)$ & $1.67(0.52$ to 5.34$)$ & $0.328 \ddagger$ \\
\hline Renal impairment & $4(3.23)$ & 21 (3.78) & $0.86(0.29$ to 2.55$)$ & $0.806 \ddagger$ \\
\hline Hepatic impairment & $15(12.10)$ & $91(16.16)$ & $0.71(0.40$ to 1.28$)$ & $0.256 \dagger$ \\
\hline Bowel obstruction & $9(7.26)$ & $27(4.80)$ & $1.55(0.71$ to 3.39$)$ & $0.265 \dagger$ \\
\hline Burette & $78(62.90)$ & $359(63.77)$ & 0.96 (0.64 to 1.44$)$ & $0.857 \dagger$ \\
\hline Alternating bags of fluid & $26(20.97)$ & $134(23.80)$ & $0.85(0.53$ to 1.36$)$ & $0.499 \dagger$ \\
\hline Potassium-containing IV fluid & $30(24.19)$ & $153(27.18)$ & $0.86(0.54$ to 1.34$)$ & $0.496 \dagger$ \\
\hline Additive & $6(4.84)$ & $54(9.59)$ & $0.48(0.20$ to 1.14$)$ & $0.090 \dagger$ \\
\hline Parenteral nutrition & $1(0.81)$ & $19(3.37)$ & $0.23(0.03$ to 1.76$)$ & $0.149 \ddagger$ \\
\hline Separate drug infusions & $22(17.74)$ & $92(16.34)$ & $0.96(0.63$ to 1.47$)$ & $0.704 \dagger$ \\
\hline IV pain relief & $21(16.94)$ & $123(21.85)$ & $0.73(0.44$ to 1.21$)$ & $0.224 \dagger$ \\
\hline Monday and Friday & $58(46.78)$ & $213(37.83)$ & $1.44(0.98$ to 2.14$)$ & $0.065 \dagger$ \\
\hline Day shift (9:00 to $16: 00$ hours) & $58(46.77)$ & $302(53.64)$ & $1.32(0.89$ to 1.94$)$ & $0.166 \dagger$ \\
\hline No of co-morbidities & $2(1-3)$ & $2(0-3)$ & $1.01(0.92$ to 1.11$)$ & $0.943 \S$ \\
\hline No of IV lines & $1(1-2)$ & $1(1-2)$ & $1.31(0.94$ to 1.83$)$ & $0.142 \S$ \\
\hline No of doses given per day & $12(9-18)$ & $13(9-19)$ & $1.02(0.99$ to 1.05$)$ & $0.094 \S$ \\
\hline No of regular IV medications & $2(1-3)$ & $2(1-3)$ & $1.15(0.99$ to 1.35$)$ & $0.107 \S$ \\
\hline No of regular non-IV medications & $4(1-5)$ & $4(2-6)$ & $1.04(0.98$ to 1.11$)$ & $0.235 \S$ \\
\hline $\begin{array}{l}\text { Total no of regular medications } \\
\text { (oral + IV + topical) }\end{array}$ & $5(3-8)$ & $6(4-9)$ & $1.06(1.00$ to 1.12$)$ & $0.051 \S$ \\
\hline Level of experience of nurse & $18.3(18.0-20.0)$ & $18.6(18.0-20.0)$ & $1.05(0.95$ to 1.17$)$ & $0.248 \S$ \\
\hline Nurse to patient ratio & $0.25(0.21-0.27)$ & $0.25(0.21-0.29)$ & $3.08(0.44$ to 21.7$)$ & $0.504 \S$ \\
\hline Occupancy of bed bay & $1(1-1)$ & $1(1-1)$ & $0.76(0.18$ to 3.28$)$ & $0.707 \S$ \\
\hline
\end{tabular}

*Nominal data expressed as number (\%); continuous data expressed as median (25-75th percentile).

$+\chi^{2}$ test.

†Fisher's exact test.

§Mann-Whitney U test. 


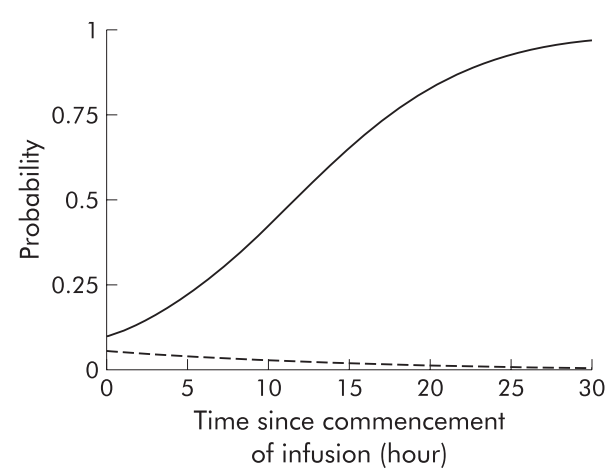

Figure 1 Impact of an IV infusion control device and duration of infusion on the probability of an error occurring. The dashed line represents the model predicted probability when an IV infusion control device is present and the solid line represents the model predicted error when an IV infusion control device is not present.

One of the most challenging tasks with studies of this nature is to assess the clinical significance of the error. For ethical reasons this has to be done using a predictive rather than observational methodology such as event scoring by a group of peers to predict probable outcome. ${ }^{26}$ In this study we have chosen to quantify the deviation in rate of administration from the prescribed rate, in part to help discuss the significance of these errors (fig 2). The median (IQR) deviation from the prescribed rate was $-47(-75$ to +33.8$) \mathrm{ml} / \mathrm{h}$. It can be seen that, for infusions prescribed at a rate between 0 and $50 \mathrm{ml} / \mathrm{h}$, there was a tendency for administration rates to be greater (median $+47 \mathrm{ml} / \mathrm{h}$ ), although for infusions prescribed above $50 \mathrm{ml} / \mathrm{h}$, administration rates were generally slower. The observed median administration rates were $-38,-59$ and $-104 \mathrm{ml} / \mathrm{h}$ for prescribed administration rates of 50-100, 100150 , and $\geqslant 150 \mathrm{ml} / \mathrm{h}$, respectively. This is of great clinical significance as the patient population was often postoperative and nil by mouth. They may therefore have become dehydrated which could have delayed recovery, caused postoperative complications, and extended hospital stay. We also wish to reiterate that the observer intervened in nearly half the errors identified, perceiving them to be of significant clinical importance.

The results found here are not dissimilar to those of other researchers who also found that administration rate errors are common. ${ }^{25}$ These researchers have suggested that the error was often deliberate-that is, individuals were aware that the administration rate deviated from that prescribed but did not consider it to be clinically significant-and concluded that use of infusion control devices and educational training would prevent rapid administration of bolus doses. ${ }^{19}$ At first glance these conclusions appear similar to ours, although it should be remembered that the majority of infusions in this study were actually given too slowly (fig 2), which is in direct contrast to Taxis and Barber. ${ }^{19}$ This could be due to the type of infusion studied (continuous versus intermittent) but may also be a deliberate event-that is, slowing the infusion rates to reduce the number of bags to be infused over a working shift. While it is not possible to confirm these ideas, it is possible to reflect upon feedback from staff during the study which suggested that some errors were of a deliberate nature. Specifically, volumetric devices (burettes) to control the rate of administration were often used inappropriately, with staff indicating they did not perceive enough time was available to check administration rates on an hourly basis (as is hospital policy). This policy was introduced in an attempt to ensure drip rates remain constant throughout an infusion as movement and gravitational forces can significantly impact upon administration rate. Staff indicated that they preferred to run fluid in freely

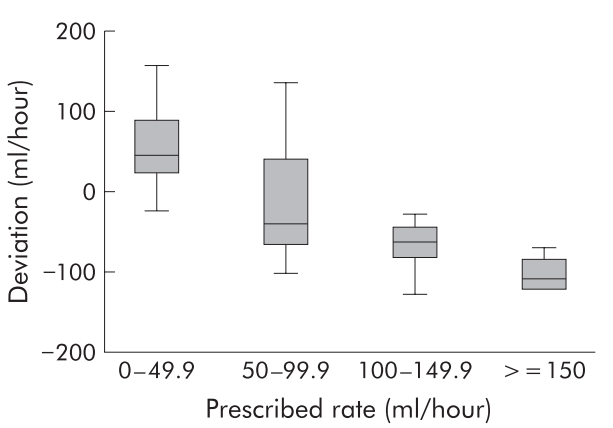

Figure 2 Deviation of observed administration rate from prescribed administration rate. The extremities of the box represent the second and third quartiles with the median shown as the solid line in the middle of the box. The whiskers span is 1.5 times the interquartile range.

through the chamber of the burette for infusions prescribed at a slow rate in order to minimise continual checking. They did not perceive that any detrimental patient outcomes would result, which probably explains why slower prescribed infusions were generally given too quickly. The inappropriate use of burettes and checking of drip rate may therefore explain why the presence of a burette or lack thereof did not seem to be an important variable in error occurrence (table 5).

The other important predictor for errors in this study was the duration of the infusion. In the absence of an IV infusion control device, the error probability increased as the duration of the infusion lengthened. This probably occurs because patients administered fluids via controlled regulator giving sets require frequent monitoring and adjustment of the regulator clamp, as described above, which we know was rarely performed. Despite initial administration rates being accurately set, patient movement changes administration rate which is an occurrence that will inevitably increase over time. Of additional interest was the observation that error probability decreased with increasing infusion duration (in the presence of an IV infusion control device), which might occur for two reasons. Firstly, flow rates can easily be checked with such devices and the number of checks increases with time and, secondly, patient movement does not interfere with flow rate, unlike gravitational devices.

Apart from administration rate errors, dose omissions, extra/unordered fluids, wrong fluids and wrong patient errors were also identified. Dose omissions may have occurred as prescribers did not inform nursing staff of changes to a patient's fluid orders or prescription charts were not checked following specific surgical or medical consults. Errors from extra/unordered fluids or wrong fluids could be attributable to the style of the prescription chart (insufficient space for writing prescriptions), as well as the lack of doses specified by the prescriber. Other factors that contributed towards MAEs but could not be supported by the logistic regression model included the lack of all permanent staff on the ward, presence of peripheral lines, absence of nasogastric feeds, a previous non-invasive procedure, the number of days on IV fluids, the number of IV fluid orders, poorer renal function, and increasing age. At face value this might suggest that patients were generally healthier (excluding age and renal function) which could indicate that less nursing time was spent with them. Intuitively this seems plausible, as patients who are more ill usually require "intensive" nursing resulting in more frequent checks of patient status and medications given.

The study is not without limitations, with some subjects overlooked during data collection and various errors not detectable for each observation. However, we do not believe the gaps in data collection were of significance as policies, procedures, and staff mixes were similar across data 


\section{Key messages}

- Medication administration errors from continuous IV infusions occurred in nearly one fifth of doses administered to patients.

- Errors in rate of administration were the most common type of error found.

- The use of IV infusion control devices significantly decreased errors that arose from wrong rates of administration.

- Increasing infusion duration contributed towards error occurrence when an IV infusion control device was not used.

- A non-punitive reporting system should be used to increase knowledge about administration errors in daily practice.

collection and non-collection times. Also, $85 \%$ of fluids were prescribed over 8 hours (or slower), and these infusions would have been identified in the prior or superseding data collection window. A small percentage of fluids (around 9\%) would have required addition of electrolytes during the time gaps, and it is recognised that observation of these additions has been missed. However, as fluid selection and electrolyte additions were only observed on $13 \%$ of occasions, the impact on the results presented here is perceived to be minimal. The apparent lack of observations on fluid selection and electrolyte additions might also appear to be of concern and cast doubt as to the certainty of error prevalence in the wrong electrolyte category. It is true that they could be underrepresented as a result of this methodology, although examination of the data revealed that $91 \%$ of fluids in this study were either premixed potassium chloride infusions or devoid of any additional additives. The apparent small number of observations on fluid selection and electrolyte addition may not therefore be of concern. It is also possible that dose omissions may be under-represented, despite regular medication chart reviews, as immediate (stat) doses were primarily identified when the observer visibly saw a bag of IV fluid on the ward. Similarly, to minimise patient disturbance, night shift observations between 00.01 and 03.00 hours were only permitted if the nurse was preparing or administering an IV fluid. Errors in administration rate without the presence of the nurse could not therefore be detected during this time period.

Regardless of the practical and technical difficulties while conducting this study, we believe the design was robust, with minimal bias from the direct observational technique, ${ }^{27}$ and the results describe the events observed. The inability to detect some factors thought to contribute towards errors a priori (such as level of nursing experience ${ }^{28}$ ) could have been due to methodology or type II statistical errors, or perhaps represent the particular study institution and differing practices. We believe that MAEs involving continuous IV infusions are common and the proposed mechanisms identified in this study seem plausible. We suggest that IV infusion control devices are used for (1) patients at risk of overhydration or underhydration-for example, heart failure or diabetic ketoacidosis; (2) infusions due to run for 12 hours or longer; and (3) infusions that may cause significant harm if infused too rapidly-for example, potassium chloridecontaining infusions. We also suggest that education sessions are provided to nursing staff, paying specific attention to infusion rates and the consequences that can arise from too rapid or too slow administration. Checklists should be introduced on wards to encourage nurses to monitor administration rates regularly, and administrators should be encouraged to evaluate staffing mix to increase the ratio of permanent to pooled staff.

\section{ACKNOWLEDGEMENTS}

The authors thank the nursing staff on the general surgical wards at the Princess Alexandra Hospital and Ms Carol Reid RN of the Adverse Drug Event Prevention project for her assistance with training, familiarisation with surgical patients, mechanism of intravenous drug preparation and delivery, infusion devices and introduction to the wards and staff.

\section{Authors' affiliations}

P Y Han, I D Coombes, B Green, The School of Pharmacy, University of Queensland, Brisbane, Australia and Department of Pharmacy, Princess Alexandra Hospital, Brisbane, Australia

I D Coombes, Adverse Drug Event Prevention Project, Queensland Health, Australia

\section{REFERENCES}

1 Johnston RV, Boiteau P, Charlebois K, Long S, David U. Responding to tragic error: lessons from Foothills Medical Centre. CMAJ 2004; 170:1659-60.

2 Brennan TA, Leape LL, Laird NM, et al. Incidence of adverse events and negligence in hospitalized patients: results of the Harvard Medical Practice Study I. N Engl J Med 1991;324:370-6.

3 Wilson RM, Runciman WB, Gibberd RW, et al. The Quality in Australian Health Care Study. Med J Aust 1995; 163:458-71

4 Bates DW, Cullen DJ, Laird N, et al. Incidence of adverse drug events and potential adverse drug events: implications for prevention. JAMA 1995;274:29-34.

5 Classen DC, Pestotnik SL, Evans RS, et al. Adverse drug events in hospitalized patients - excess length of stay, extra costs, and attributable mortality. JAMA 1997;277:301-6.

6 Bates DW, Spell N, Cullen DJ, et al. The costs of adverse drug events in hospitalized patients. JAMA 1997;277:307-11.

7 Moore N, Lecointre $D$, Noblet $C$, et al. Frequency and cost of serious adverse drug reactions in a department of general medicine. $\mathrm{Br} J$ Clin Pharmacol 1998;45:301-8.

8 Johnson JA, Bootman JL. Drug-related morbidity and mortality: a cost-ofillness model. Arch Intern Med 1995; 155:1949-56.

9 Ridge KW, Jenkins DB, Noyce PR, et al. Medication errors during hospital drug rounds. Qual Health Care 1995;4:240-3.

10 Barker KN, Flynn EA, Pepper GA, et al. Medication errors observed in 36 health care facilities. Arch Intern Med 2002;162:1897-903.

11 Bates DW. Frequency, consequences and prevention of adverse drug events. J Qual Clin Pract 1999;19:13-7.

12 Reason J. Human error: models and management. BMJ 2000;320:768-70.

13 Vincent C. Understanding and responding to adverse events. N Engl J Med 2003;348:1051-6.

14 Leape LL, Bates DW, Cullen DJ, et al. Systems analysis of adverse drug events. JAMA 1995;274:35-43.

15 Armitage G, Knapman $\mathrm{H}$. Adverse events in drug administration: a literature review. J Nurs Manag 2003;11:130-40.

$16 \mathrm{O}^{\prime}$ Shea $\mathrm{E}$. Factors contributing to medication errors: a literature review. J Clin Nurs 1999;8:496-504.

17 Ho CYW, Dean BS, Barber ND. When do medication administration errors happen to hospital inpatients? Int J Pharm Pract 1997;5:91-6.

18 Kaushal R, Bates DW, Landrigan C, et al. Medication errors and adverse drug events in pediatric inpatients. JAMA 2001;285:2114-20.

19 Taxis K, Barber N. Ethnographic study of incidence and severity of intravenous drug errors. BMJ 2003;326:684-7.

20 Bruce J, Wong I. Parenteral drug administration errors by nursing staff on an acute medical admissions ward during day duty. Drug Saf 2001;24:855-62.

21 Hartley GM, Dhillon S. An observational study of the prescribing and administration of intravenous drugs in a general hospital. Int J Pharm Pract 1998:6:38-45.

22 Barker KN. Data collection techniques: observation. Am J Hosp Pharm 1980;37:1235-43

23 Hintze J. NCSS and PASS. Number cruncher statistical systems. Utah: Kaysville, 2001

24 Beal SL, Sheiner LB. NONMEM user's guide: Part I. San Francisco: University of California, 1992.

25 Taxis K, Barber N. Causes of intravenous medication errors: an ethnographic study. Qual Saf Health Care 2003;12:343-8.

26 Dean BS, Barber ND. A validated reliable method of scoring the severity of medication errors. Am J Health-Syst Pharm 1999;56:57-62.

27 Dean B, Barber N. Validity and reliability of observational methods for studying medication administration errors. Am J Health-Syst Pharm 2001;58:54-9

28 Hunt ML Jr, Rapp RP. Intravenous medication errors. J Intravenous Nurs 1996; 19(3S):S9-15 